Gut, 1973, 14, 393-398

\title{
Pharmacological characteristics of the non-striated anorectal musculature in cats
}

\author{
F. PENNINCKX, ${ }^{1}$ R. KERREMANS, AND J. BECKERS \\ From the Department of Heelkundige en Anaesthesiologische Wetenschappen, Section of Gastroenterology, \\ Akademisch Ziekenhuis St Rafaël, Leuven, Belgium
}

SUMMARY The isolated internal anal sphincter from cats shows a myogenic spontaneous rhythmic activity. Basal tension and frequency of contraction waves from internal anal sphincter strips are inhibited by muscarinic and beta-adrenergic receptors and excited by alpha-adrenergic receptors. Isoprenaline in high doses had an alpha-adrenoceptor-stimulating activity in strips from the internal sphincter. The inhibitory muscarinic receptors may be the final effectors in the anorectal reflex. The relaxing effect of acetylcholine on the internal sphincter was sometimes preceded by a temporary contraction due to the interaction of intermingled longitudinal muscle fibres. Rectal circular muscle strips contain excitatory muscarinic receptors and inhibitory alpha- and beta-adrenergic receptors. The same can be said of the strips from the longitudinal muscle layer at the anal canal and at the rectum.

The presence of alpha-excitatory and beta-inhibitory adrenergic receptors within the internal anal sphincter has been demonstrated in man and cat (Parks and Fishlock, 1967; Friedmann, 1968; Parks, Fishlock, Cameron, and May, 1969; Kerremans, 1969; Kerremans and Penninckx, 1970). The cholinergic receptors of the internal anal sphincter were studied by Friedmann (1968) and by Parks et al (1969). They concluded that the human internal anal sphincter is composed of an upper and lower part, the lower part being generally insensitive to acetylcholine whereas the upper part contracts (Parks et al, 1969) or is usually unresponsive (Friedmann, 1969). The pharmacological profile of the anorectal region was not studied and no further conclusions were drawn from these experiments. It is a current concept that gastrointestinal sphincters relax after stimulation of muscarinic receptors. However, a review of the literature shows that in vitro stimulation of these receptors in the sphincteric regions results in contraction of the circular muscle layer, eg, the cardiac sphincter (Ellis, Kauntze, and Trounce, 1960; Christensen and Daniel, 1968), the sphincter of Oddi (Crema and Benzi, 1961; Crema and Berté, 1963; Persson, 1971), and the ileocaecocolic sphincter (Gazet and Jarrett, 1964; Gazet, 1968).

${ }^{1}$ Aspirant van het National Fonds voor Wetenschappelijk Onderzoek (NFWO).

Received for publication 24 January 1973.
If the same occurs in the internal anal sphincter, which then is the mechanism causing relaxation of the internal sphincter after rectal distension? Friedmann (1968) and Parks et al (1969) thought that relaxation of the upper part of the human internal anal sphincter induced by nicotine and other ganglion-stimulating agents is based on a release of noradrenaline or of an isoprenaline-like substance near beta receptors. Although this would provide an explanation for the reflectory relaxation of the internal sphincter in vivo, the hypothesis does not go unchallenged. The present study was undertaken to investigate the pharmacological characteristics in vitro of both circular and longitudinal smooth muscle layers at different heights in the cat anorectal region.

\section{Material and Methods}

Adult male and female cats anaesthetized with ether were used. The anus and the rectum up to about $6 \mathrm{~cm}$ above the anal margin were removed by abdominoperineal resection. The anorectal canal was opened longitudinally. After removing mucosa and submucosa, strips of circular muscle were taken, at $0,1,2,3,4,5$, and $6 \mathrm{~cm}$ proximally to the anal margin. Strips of the longitudinal muscle layer, taken at 0 to $1 \mathrm{~cm}$ and at 5 to $6 \mathrm{~cm}$ proximally to the anal margin, were prepared. The strips were 
suspended in a $100 \mathrm{ml}$ Tyrode bath at $37^{\circ} \mathrm{C}$ with a preload of 1 to $2 \mathrm{~g}$ and gassed with $95 \%$ oxygen and $5 \%$ carbon dioxide. The solution contained: $\mathrm{Nacl} 8 \mathrm{~g} ; \mathrm{Kcl} 0.2 \mathrm{~g} ; \mathrm{CaCl}_{2} 0.2 \mathrm{~g} ; \mathrm{MgCl}_{2} 0.01 \mathrm{~g}$; $\mathrm{NaH}_{2} \mathrm{PO}_{4} 0.05 \mathrm{~g} ; \mathrm{NaHCO}_{3} 1 \mathrm{~g}$; glucose $1 \mathrm{~g}$; distilled water to $1000 \mathrm{ml}$. The strips were attached to a strain gauge transducer for isometric recording of tension changes. A 15-minute accommodation period was provided, in order to obtain a steady baseline and the full development of spontaneous activity.

Overall drug effects were investigated on 97 circular and 20 longitudinal muscle strips of the anorectal region from 10 cats. Fully active concentrations of acetylcholine (Ach $10^{-4} \mathrm{M}$ ) and noradrenaline (NA $10^{-5} \mathrm{M}$ ) were used. Acetylcholine was always tested twice and the response of the second test was noted. Isoprenaline was used in a concentration of $10^{-6} \mathrm{M}$ because higher doses have an alpha-adrenergic receptor stimulating effect (cf infra). Barium chloride $\left(\mathrm{BaCl}_{2}\right) \quad 100 \mu \mathrm{g} / \mathrm{ml}$ was added before testing noradrenaline or isoprenaline when strips showed no spontaneous activity and low baseline tension. The presence of $\mathrm{BaCl}_{2}$ did not change their effect qualitatively.

In a more detailed study of drug effects 96 internal sphincter strips from 35 cats were used. The strips were taken within $1.5 \mathrm{~cm}$ proximal to the anal margin. The following drugs were used: acetylcholine chloride, adrenaline hydrochloride, barium chloride, bretyliumtosylate, gallamine triethiodide, hexamethonium bromide, hyoscine-N-butylbromide, isoprenaline hydrochloride, noradrenaline hydrochloride, phenoxybenzamine hydrochloride, propranolol hydrochloride, prostigmine metylsulphate. Acetylcholine was used in a concentration of $10^{-4}$ or $10^{-5} \mathrm{M}$ and in cumulative doses from $10^{-10}$ to $10^{-3} \mathrm{M}$. Adrenaline, noradrenaline, and isoprenaline were tested in cumulative doses from $10^{-10}$ to $10^{-4} \mathrm{M}$. Concentrations refer to the salts. Drugs were added to the bath solution and their action was recorded for two to five minutes. Blocking agents were allowed to act for up to 15 minutes.

\section{Results}

\section{SPONTANEOUS ACTIVITY}

Most of the longitudinal strips and the proximal circular strips had no spontaneous activity (fig 1 $B, C, D)$. If present the frequency of the contractions was less than $10 / \mathrm{min}$. Stretch-induced contractions were never recorded. The distal circular strips, corresponding to the internal anal sphincter, usually showed continuous rhythmic activity for more than three hours. A steady baseline, on which sinusoidal or composed contraction waves were superimposed, was maintained (fig $1 \mathrm{~A})$. The mean frequency of the contractions was $22 / \mathrm{min}$ (10 to $40 / \mathrm{min}$ ). The highest frequency was recorded in distal strips. These results are consistent with earlier studies on the mechanical activity of the internal anal sphincter in man and cat in vitro and in vivo (Kerremans, 1968, 1969; Kerremans and Penninckx, 1970). The spontaneous activity of the internal sphincter strips was not inhibited by hyoscine $\left(10^{-4} \mathrm{M}\right)$, hexamethonium $\left(10^{-4} \mathrm{M}\right)$, bretylium $\left(10^{-4} \mathrm{M}\right)$, and phenoxybenzamine $\left(10^{-7} \mathrm{M}\right)$. Higher doses of the latter drug inhibited or sometimes abolished the spontaneous contractions of the sphincter strips.

OVERALL DRUG EFFECTS ON CIRCULAR AND LONGITUDINAL ANORECTAL MUSCLE STRIPS Distal circular strips (from 0 to just above $2 \mathrm{~cm}$ above the anal margin) usually relaxed after acetylcholine and always contracted after noradrenaline (fig $1 \mathrm{~A})$ whereas the most proximal strips always contracted after acetylcholine and relaxed after noradrenaline (fig $1 \mathrm{C}$ ). The reversal of the response to noradrenaline was mainly in circular strips taken at $4 \mathrm{~cm}$ from the anal margin, whereas the reversal of the response to acetylcholine was always recorded more distally, ie, at 2 to $2.5 \mathrm{~cm}$. Strips of the distal and proximal longitudinal muscle layer contracted after acetylcholine and relaxed after noradrenaline (fig $1 \mathrm{~B}, \mathrm{D})$. Isoprenaline induced relaxation in both the circular and longitudinal strips. The results obtained in 10 cats are summarized in table I.

\section{DETAILED ANALYSIS OF THE RESPONSES OF INTERNAL ANAL SPHINCTER STRIPS TO DRUGS}

\section{Acetylcholine}

Ninety-six circular strips of the distal $1.5 \mathrm{~cm}$, corresponding to the internal sphincter region, were stimulated with acetylcholine; the response was relaxation in $75 \%$ of the strips, always accompanied by a decrease in or disappearance of contraction waves (fig $1 \mathrm{~A}$ ). The relaxation was sometimes temporary. If repeated identical doses of acetylcholine were added to the bath solution, adaptation occurred. Occasionally a contraction component, preceding the relaxation, appeared and progressively became more important (fig $3 \mathrm{~A}, \mathrm{~B}$ ). Relaxation toacetylcholine was potentiated by prostigmine and prevented by hyoscine. Gallamine had no effect. Hexamethonium did not inhibit the relaxation or only partially.

The response of internal sphincter strips to acetylcholine was biphasic, ie, contraction followed 
A
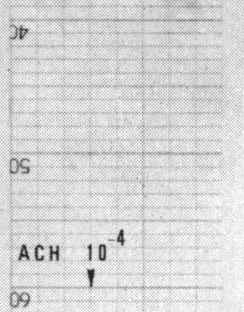

NA $10^{-5}$

oc

B
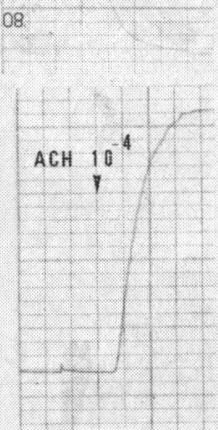

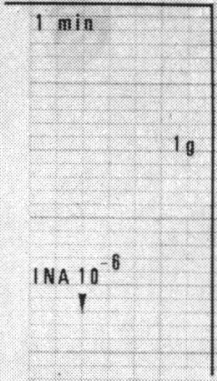

C
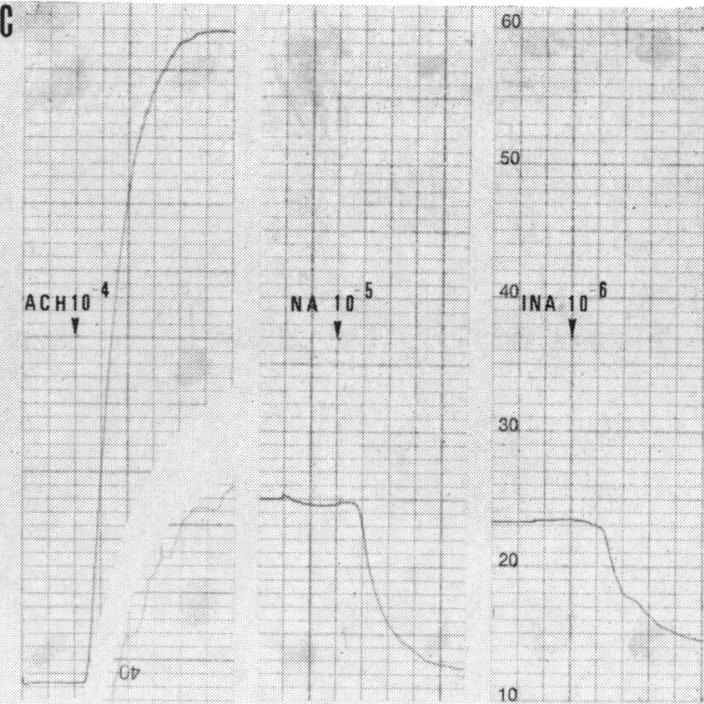

D

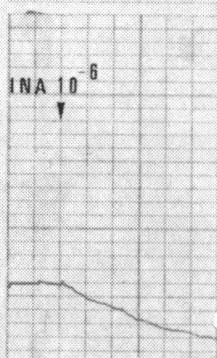

Fig 1 A Responses of circular smooth muscle strip taken at $0.5 \mathrm{~cm}$ above the level of the anal margin. This strip shows a spontaneous rhythmic activity. Relaxation with disappearance of contraction waves occurs after acetylcholine $10^{-4} \mathrm{M}$ and isoprenaline $10^{-6} \mathrm{M}$. Noradrenaline $10^{-5} \mathrm{M}$ causes contraction.

B Effects of the same drugs on a longitudinal smooth muscle strip taken at the anal canal. This strip shows the same responses as the rectal circular (C) and the rectal longitudinal strip (D).

C Responses of a circular strip taken at $5 \mathrm{~cm}$ above the level of the anal margin. The effects of acetylcholine and noradrenaline are reversed in comparison with those seen in the distal circular strip (A).

D The responses of a rectal longitudinal muscle strip to acetylcholine, noradrenaline, and isoprenaline are the same as those of the distal longitudinal strip (B).

\begin{tabular}{|c|c|c|c|c|c|c|c|c|c|c|c|c|c|c|c|c|c|c|c|c|c|c|c|c|c|c|c|c|c|c|c|}
\hline \multirow[t]{2}{*}{ Muscle Strip } & \multicolumn{11}{|c|}{ Acetylcholine $\left(10^{-4} \mathrm{M}\right)$} & \multicolumn{10}{|c|}{ Noradrenaline $\left(10^{-5} \mathrm{M}\right)$} & \multicolumn{10}{|c|}{ Isoprenaline $\left(10^{-6} \mathrm{M}\right)$} \\
\hline & 1 & 2 & 3 & 4 & 5 & 6 & 7 & & 8 & 9 & 10 & 1 & 2 & 3 & 4 & 5 & 6 & 7 & 8 & 9 & 10 & 1 & 2 & 3 & 4 & 5 & 6 & 7 & 8 & 9 & 10 \\
\hline $\begin{array}{l}\text { Circ. } 0 \mathrm{~cm} \\
\text { Circ. } 0.5 \mathrm{~cm} \\
\text { Circ. } 1 \mathrm{~cm} \\
\text { Circ. } 1.5 \mathrm{~cm} \\
\text { Circ. } 2 \mathrm{~cm} \\
\text { Circ. } 2.5 \mathrm{~cm} \\
\text { Circ. } 3 \mathrm{~cm} \\
\text { Circ. } 3.5 \mathrm{~cm} \\
\text { Circ. } 4 \mathrm{~cm} \\
\text { Circ. } 4.5 \mathrm{~cm}\end{array}$ & $\begin{array}{l}\uparrow \\
\downarrow \\
\downarrow\end{array}$ & $\begin{array}{l}\uparrow \downarrow \\
\downarrow \\
\downarrow \\
\downarrow \\
\uparrow \\
\uparrow\end{array}$ & $\begin{array}{l}\uparrow \downarrow \\
\uparrow \downarrow \\
\downarrow \\
\downarrow \\
\downarrow \\
\uparrow \\
\uparrow\end{array}$ & $\begin{array}{l}\uparrow \\
\downarrow \\
\downarrow \\
\downarrow \\
\downarrow\end{array}$ & $\begin{array}{l}\downarrow \\
\vdots \\
\vdots \\
\vdots \\
\uparrow \\
\uparrow\end{array}$ & $\begin{array}{l}\uparrow \\
\uparrow \\
\uparrow \\
\downarrow \\
\uparrow \\
\uparrow \\
\uparrow \\
\uparrow \\
\uparrow\end{array}$ & & 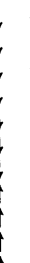 & $\begin{array}{l}\uparrow \downarrow \\
\uparrow \downarrow \\
\uparrow \downarrow \\
\uparrow\end{array}$ & $\begin{array}{l}\uparrow \downarrow \\
\downarrow \\
\downarrow \\
\downarrow \\
\uparrow \\
\uparrow \\
\uparrow \\
\uparrow \\
\uparrow\end{array}$ & $\begin{array}{l}\uparrow \downarrow \\
\uparrow \downarrow \\
\downarrow \\
\downarrow \\
\uparrow \\
\uparrow \\
\uparrow \\
\uparrow \\
\uparrow \\
\uparrow\end{array}$ & $\begin{array}{l}\uparrow \\
\uparrow \\
\uparrow\end{array}$ & $\begin{array}{l}\uparrow \\
\uparrow \\
\uparrow \\
\uparrow \\
\uparrow \\
\uparrow\end{array}$ & $\begin{array}{l}\uparrow \\
\uparrow \\
\uparrow \\
\uparrow \\
\uparrow \\
\uparrow \\
\uparrow\end{array}$ & $\begin{array}{l}\uparrow \\
\uparrow \\
\uparrow \\
\uparrow \\
\uparrow \\
\uparrow\end{array}$ & $\begin{array}{l}\uparrow \\
\uparrow \\
\uparrow \\
\uparrow \\
\uparrow \\
\uparrow \\
\uparrow \\
\downarrow \\
\downarrow\end{array}$ & $\begin{array}{l}\uparrow \\
\uparrow \\
\uparrow \\
\uparrow \\
\uparrow \\
\uparrow \\
\uparrow \\
0 \\
\downarrow\end{array}$ & $\begin{array}{l}\uparrow \\
\uparrow \\
\uparrow \\
\uparrow \\
\uparrow \\
\uparrow \\
\uparrow \\
\uparrow \\
\downarrow\end{array}$ & $\begin{array}{l}\uparrow \\
\uparrow \\
\uparrow \\
\uparrow \\
\uparrow \\
\uparrow \\
\uparrow \\
\uparrow \\
0\end{array}$ & $\begin{array}{l}\uparrow \\
\uparrow \\
\uparrow \\
\uparrow \\
\uparrow \\
\uparrow \\
\uparrow \\
\uparrow \\
\downarrow \\
0\end{array}$ & $\begin{array}{l}\uparrow \\
\uparrow \\
\downarrow \\
\uparrow \\
\uparrow \\
\uparrow \\
\uparrow \\
\uparrow \\
\uparrow \\
\uparrow\end{array}$ & $\downarrow$ & $\begin{array}{l}\downarrow \\
\downarrow \\
\vdots \\
\downarrow \\
\downarrow\end{array}$ & $\begin{array}{l}\downarrow \\
\vdots \\
\vdots \\
\vdots \\
\downarrow\end{array}$ & $\begin{array}{l}\downarrow \\
\downarrow \\
\downarrow \\
\downarrow \\
\downarrow\end{array}$ & $\begin{array}{l}0 \\
0 \\
\downarrow \\
\downarrow \\
\vdots \\
\downarrow \\
\downarrow \\
\downarrow\end{array}$ & $\begin{array}{l}\downarrow \\
\downarrow \\
\downarrow \\
\downarrow \\
\downarrow \\
\downarrow\end{array}$ & $\begin{array}{l}\downarrow \\
\downarrow \\
\downarrow \\
\downarrow\end{array}$ & $\begin{array}{l}\downarrow \\
\mathbf{0} \\
\downarrow \\
\downarrow \\
\downarrow\end{array}$ & $\begin{array}{l}\downarrow \\
\vdots \\
\downarrow \\
\downarrow \\
0\end{array}$ & 0 \\
\hline $\begin{array}{l}\text { Circ. } 5 \mathrm{~cm} \\
\text { Circ. } 6 \mathrm{~cm} \\
\text { Circ. } 8 \mathrm{~cm}\end{array}$ & $\uparrow$ & $\uparrow$ & $\uparrow$ & $\uparrow$ & $\uparrow$ & $\uparrow$ & & 1 & $\stackrel{\uparrow}{\uparrow}$ & $\uparrow$ & $\uparrow$ & $\downarrow$ & $\downarrow$ & $\mathbf{0}$ & $\downarrow$ & $\downarrow$ & $\begin{array}{l}\downarrow \\
0\end{array}$ & $\downarrow$ & $\begin{array}{l}0 \\
\downarrow \\
0\end{array}$ & $\begin{array}{l}\downarrow \\
\downarrow\end{array}$ & $\begin{array}{l}0 \\
\downarrow\end{array}$ & $\downarrow$ & $\downarrow$ & $\mathbf{0}$ & $\downarrow$ & $\begin{array}{l}0 \\
0\end{array}$ & $\begin{array}{l}1 \\
0\end{array}$ & $\downarrow$ & $\begin{array}{l}\mathbf{0} \\
\downarrow\end{array}$ & $\begin{array}{l}\mathbf{0} \\
\downarrow\end{array}$ & 1 \\
\hline $\begin{array}{l}\text { Long. } 0-1 \mathrm{~cm} \\
\text { Long. } 5.6 \mathrm{~cm}\end{array}$ & $\uparrow$ & $\uparrow$ & $\uparrow$ & $\begin{array}{l}\uparrow \\
\uparrow\end{array}$ & $\uparrow$ & $\uparrow$ & & & $\uparrow$ & $\uparrow$ & $\uparrow$ & $\downarrow$ & $\downarrow$ & $\downarrow$ & $\begin{array}{l}0 \\
\downarrow\end{array}$ & $\downarrow$ & $\downarrow$ & $\downarrow$ & $\downarrow$ & $\downarrow$ & $\downarrow$ & $\downarrow$ & $\downarrow$ & $\downarrow$ & $\downarrow$ & $\downarrow$ & $\begin{array}{l}0 \\
\downarrow\end{array}$ & $\downarrow$ & $\begin{array}{l}0 \\
\downarrow\end{array}$ & $\downarrow$ & $\downarrow$ \\
\hline
\end{tabular}

Table I Responses of the anorectal musculature to acetylcholine, noradrenaline, and isoprenaline in 10 cats 


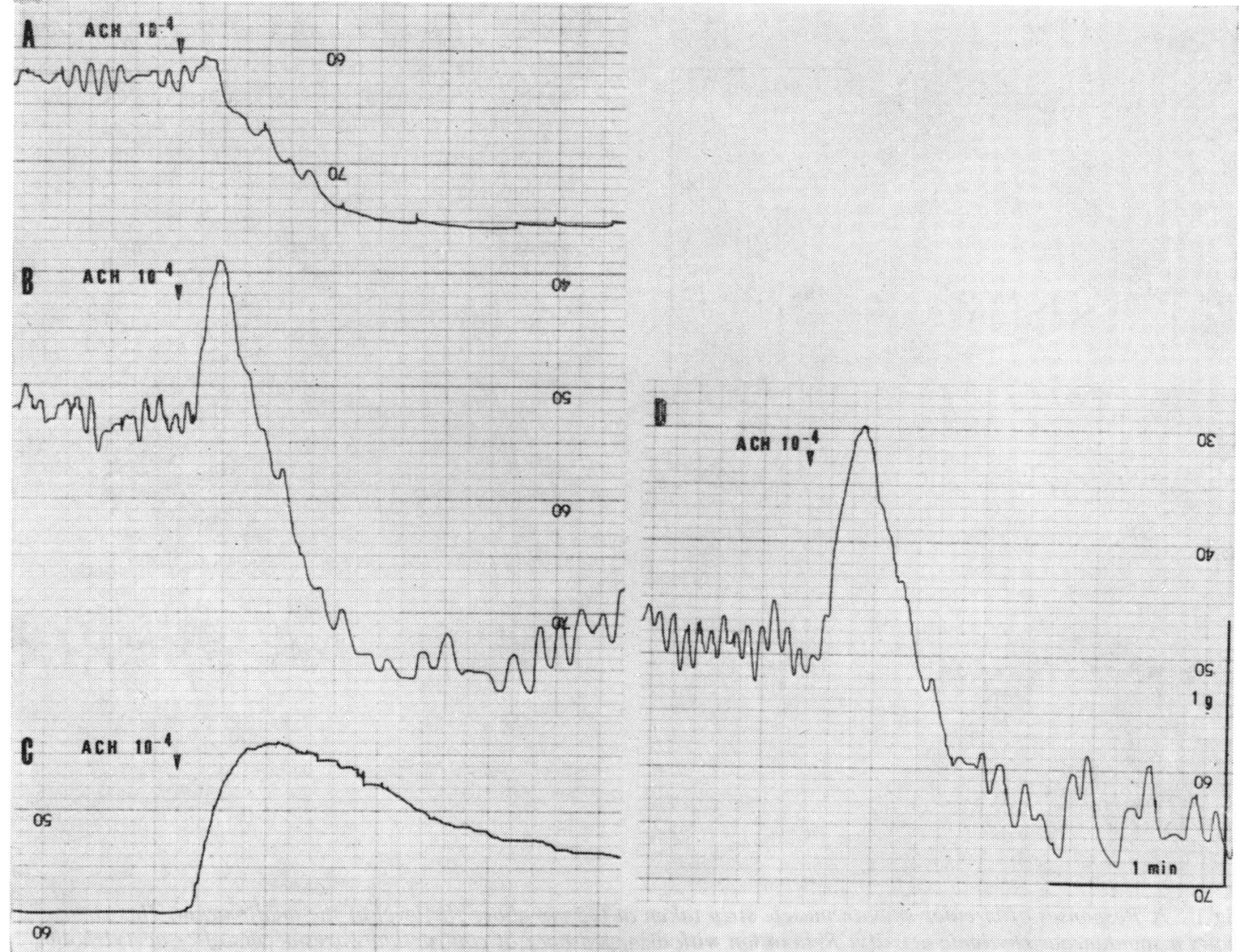

Fig. 2 A Relaxation response of a circular smooth muscle strip taken at $0.5 \mathrm{~cm}$ above the anal margin to acetylcholine $10^{-4} \mathrm{M}$.

B After repeated stimulation of the same circular strip with acetylcholine $10^{-4} \mathrm{M}$ a biphasic response is recorded.

C Acetylcholine $10^{-4} \mathrm{M}$ causes contraction of a distal longitudinal smooth muscle strip.

$\mathrm{D}$ The internal sphincter strip used in $\mathrm{A}$ and $\mathrm{B}$ is placed in series with the distal longitudinal strip used in $\mathrm{C}$.

Acetylcholine $10^{-4} \mathrm{M}$ stimulation of this combined preparation gives a biphasic response similar to the one recorded in $\mathrm{B}$.

by relaxation, in $23 \%$ of the strips. The relaxation component of the response had the same characteristics as described above. The contraction component was of short duration and was potentiated by prostigmine and inhibited by hyoscine. Gallamine had no influence. Contraction alone occurred in only two out of 20 strips taken at the level of the anal margin. Previous tension had no influence on the qualitative effect of acetylcholine. The relationship between the responses to acetylcholine and the different levels at which the strips were taken is given in table II.

\section{Adrenaline, noradrenaline, and isoprenaline}

All circular strips taken in the internal sphincter region were found to contract to adrenaline and noradrenaline in doses of $10^{-7} \mathrm{M}$ and more. The increase in baseline tension was accompanied by an increase in frequency of the contraction waves. The contraction was stronger after stimulation with noradrenaline than after adrenaline. Previous administration of phenoxybenzamine blocked the excitatory effects of both adrenaline and noradrenaline. Isoprenaline in small concentrations (about $10^{-6} \mathrm{M}$ ) had a slight or sometimes strong inhibitory action on basal tension and frequency of contraction waves. In higher concentrations $\left(10^{-4} \mathrm{M}\right)$ isoprenaline always produced contraction and increase in frequency of the contraction waves (fig $3 \mathrm{~A}$ ). In preparations which still had a spontaneous activity after alpha-adrenoceptor blocking 


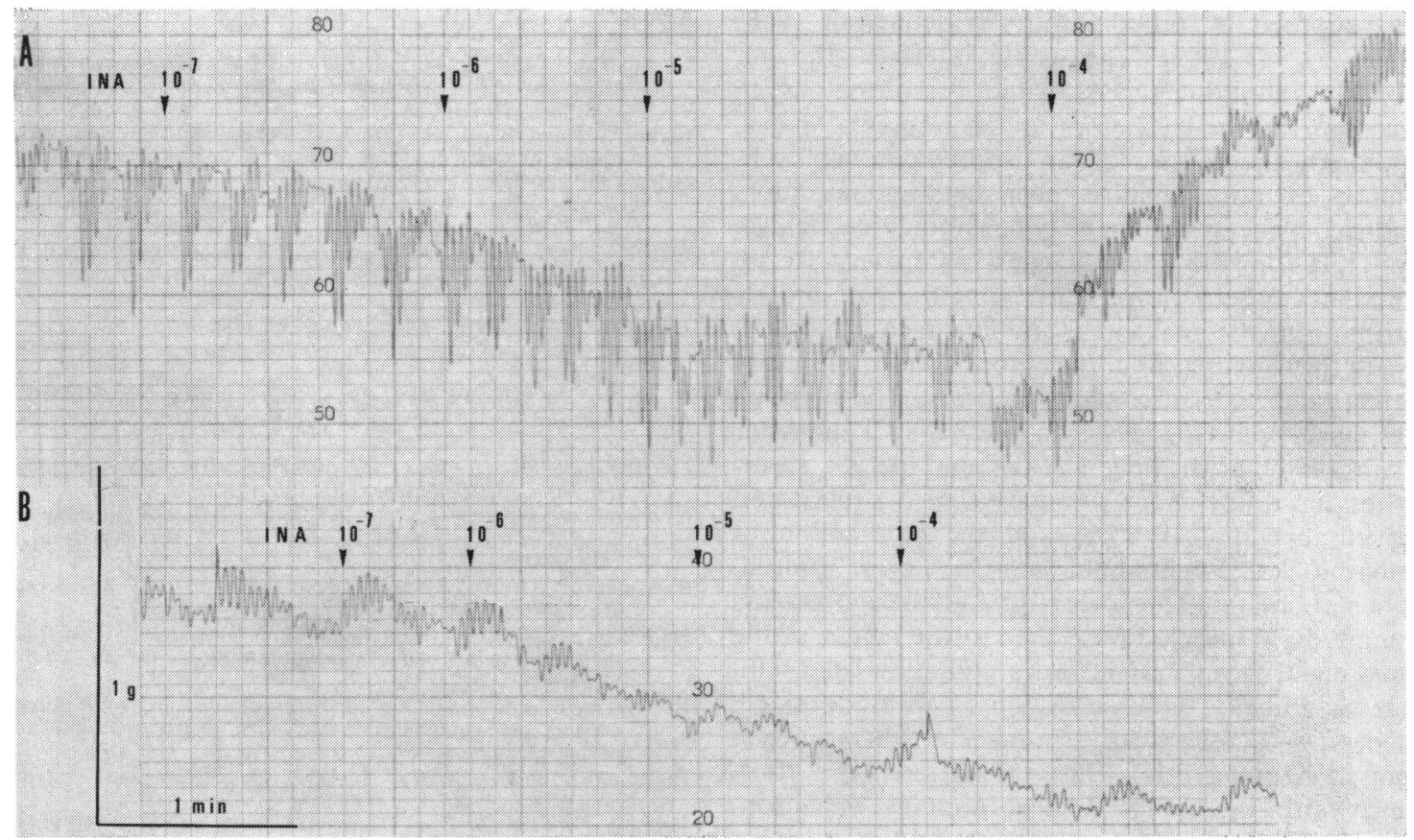

Fig. 3 A Isoprenaline in small concentrations $\left(10^{-7}, 10^{-6}\right.$, and $\left.10^{-5} \mathrm{M}\right)$ causes partial relaxation in a circular strip taken at $0.5 \mathrm{~cm}$ above the anal margin. Isoprenaline $10^{-4} \mathrm{M}$ produces contraction.

B After previous administration of phenoxybenzamine $10^{-4} \mathrm{M}$, isoprenaline $10^{-4} \mathrm{M}$ has the reverse effect.

\begin{tabular}{llll}
\hline $\begin{array}{l}\text { Level from the } \\
\text { Anal Margin } \\
(\mathrm{cm})\end{array}$ & Number of Strips & \\
\cline { 2 - 4 } & $\begin{array}{l}\text { Contraction } \\
\uparrow\end{array}$ & Biphasic & $\begin{array}{c}\text { Relaxation } \\
\downarrow\end{array}$ \\
\hline 0 & $2(10 \%)$ & $12(60 \%)$ & $6(30 \%)$ \\
$0 \cdot 5$ & 0 & $5(33 \cdot 3 \%)$ & $10(66 \cdot 7 \%)$ \\
1 & 0 & $2(16 \cdot 6 \%)$ & $10(83 \cdot 4 \%)$ \\
1.5 & 0 & $1(10 \%)$ & $9(90 \%)$ \\
\hline
\end{tabular}

Table II Relationship between the response to acetylcholine and the different levels of circular strips taken in the internal sphincter region

with phenoxybenzamine $\left(10^{-7}\right.$ to $\left.10^{-4} \mathrm{M}\right)$, a reverse effect, ie, relaxation, was induced by high doses of isoprenaline (fig 2 B).

\section{Discussion and Conclusions}

The spontaneous rhythmic activity of the isolated internal anal sphincter resembles the anal motility recorded in vivo in cats (Kerremans et al, 1970), and significantly differs from the spontaneous activity of rectal muscle strips. Probably myogenic by nature, it resists treatment with hyoscine, hexamethonium, bretylium, and phenoxybenzamine. High doses of phenoxybenzamine-inhibit the contractions of the sphincter, but this may be a non-specific effect.

From our investigations it can be concluded that the internal anal sphincter contracts when noradrenaline, and usually relaxes when isoprenaline is added, suggesting that the sphincter contains alphaexcitatory and beta-inhibitory adrenergic receptors. Isoprenaline in high doses seems to have alphaadrenoceptor-stimulating activity. This was also reported in a study in vivo by Giudicelli and Lefèvre (1967).

Our investigations give no pharmacological proof of the bipartite division of the internal anal sphincter 
as proposed by other authors (Friedmann, 1968; Parks et al, 1969). The whole internal sphincter contains inhibitory muscarinic receptors, which may be the final effectors in the anorectal reflex, although the release of an isoprenaline-like substance or noradrenaline near beta-adrenoceptors induced by acetylcholine may be another mechanism for relaxing the internal anal sphincter. Rectal circular muscle strips and longitudinal muscle strips from the anal canal and the rectum contain excitatory muscarinic receptors and inhibitory alpha- and beta-adrenergic receptors. The biphasic response, occurring mostly in internal anal sphincter strips, taken at the height of the anal margin, seems to be the result of the summation of the relaxation of circular muscle fibres and the contraction of intermingled longitudinal muscle fibres. Indeed, when an internal sphincter strip and a strip from the longitudinal muscle layer taken at the height of the anal canal are placed in series and stimulated with acetylcholine, a biphasic response can be obtained, depending on the relative number of fibres in each muscle strip (fig. 3 D). This explanation is in accordance with the morphological findings of Shropshear (1964), Wongphaet (1965), and Kerremans (1969). The transition from relaxation into a biphasic response to acetylcholine, as sometimes seen in distal internal sphincter strips, is probably based on the fact that internal sphincter fibres adapt to acetylcholine, whereas longitudinal muscle fibres show no adaptation. So the contraction component caused by the intermingled longitudinal fibres can appear and/or become progressively more important (fig. 3 B).
References

Christensen, J., and Daniel, E. E. (1968). Effects of some autonomic drugs on circular esophageal smooth muscle. J. Pharmacol. exp. Ther., 159, 243-249.

Crema, A., and Benzi, G. (1961). Comportamento in vitro dello sfintere di Oddi di alcuni animali. Arch. Fisiol., 60, 374-386.

Crema, A., and Berté, F. (1963). Action of sympathomimetic drugs on the isolated junction of the bile duct and duodenum. Brit. J. Pharmacol., 20, 221-229.

Ellis, F. G., Kauntze, R., and Trounce, J. R. (1960). The innervation of the cardia and lower oesophagus in man. Brit. J. Surg., 47, 466-472.

Friedmann, C. A. (1968). The action of nicotine and catecholamines on the human internal anal sphincter. Amer. J. dig. Dis., 13, 428-431.

Gazet, J. C., and Jarrett, R. J. (1964). The ileocaeco-colic sphincter, studies in vitro in man, monkey, cat and dog. Brit.J. Surg., 51, 368-370.

Gazet, J. C. (1968). The surgical significance of the ileo-caecal junction. Ann. roy. Coll. Surg. Engl., 43, 19-38.

Giudicelli, R., and Lefèvre, F. (1967). Sur les effets alpha-adrénergiques des fortes doses d'isoprénaline. C.R. Soc. Biol. (Paris), 161, 284-288.

Kerremans, R. (1968). Electrical activity and motility of the internal anal sphincter. Acta gastro-ent. belg., 31, 465-482.

Kerremans, R. (1969). Morphological and Physiological Aspects of Anal Continence and Defaection (Aggregaatthesis). Arscia, Brussels.

Kerremans, R., and Penninckx, F. (1970). A study in vivo of adrenergic receptors in the rectum and in the internal anal sphincter of the cat. Gut, 11, 709-714.

Parks, A. G., and Fishlock, D. J. (1967). Catecholamines. Proc. roy. Soc. Med., 60, 217.

Parks, A. G., Fishlock, D. J., Cameron, J. D. H., and May, H. (1969). Preliminary investigation of the pharmacology of the human internal anal sphincter. Gut, 10, 674-677.

Persson, C. G. A. (1971). Adrenoceptor functions in the cat choledochoduodenal junction in vitro. Brit. J. Pharmacol., 42, 447 461.

Shropshear, G. (1964). Anatomic basis for anorectal disease. Dis. Colon Rect., 7, 399-407.

Wongphaet, S. (1965). Die funktionelle Anatomie des Enddarmes. Gegenbaurs morph. Jb., 107, 281-325. 
Clinical Genetics 2nd edition edited by Arnold Sorsby. (Pp. xi + 646; illustrated. 117.00.) Butterworth Group, London. 1973. This is a comprehensive textbook of clinical genetics, with contributions from 31 outstanding British and American authorities. An opening section deals with general problems, such as the taking of a family history, pharmacogenetics, immunogenetics, and lethal and sublethal malformations. Twenty-one chapters are devoted to the genetic aspects of the individual specialities, such as metabolic disorders, the muscles, the central nervous system, the haemopoietic system, and cancer. A concluding chapter lists all known syndromes. The section on the alimentary tract is covered in detail by Dr R. B. McConnell.

The Chinese Medical Journal has restarted publication this year. Formerly it was in English only, but it is now in Chinese with shortened English translations. In view of the differences between western and Chinese medical experience it is of special interest to read. In the second issue there is an account of surgery in 1230 patients with oesophageal and gastric carcinoma.

\section{Corrections}

On page 288 of the paper by J. Schrager and M. D. G. Oates (Gut, 14, 324-329), column 1, line 16 of the discussion (in glycoproteins with blood group specificity) the phrase should read correctly (in glycoproteins with blood group specificity H).

We regret that in the paper by Penninckx et al (Gut, 14, 393-398) figs 2 and 3 have been transposed. 